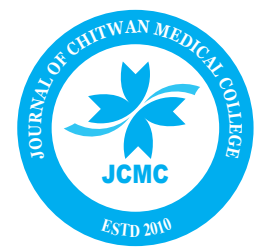

\author{
Journal of Chitwan Medical College 2020;10(31):48-53 \\ Available online at: www.jcmc.cmc.edu.np
}

\title{
EFFECTIVENESS OF NURSES-LED CARDIAC REHABILITATION PROGRAM AMONG CORONARY ARTERY DISEASE PATIENTS ATTENDING A TEACHING HOSPITAL, BHARATPUR
}

Rosy Shrestha ${ }^{1, *}$, Laxmi Rajbanshi' ${ }^{2}$, Jaya Prasad Singh ${ }^{3}$, Kshitiz Shrestha ${ }^{4}$, Sajeeb Shrestha ${ }^{5}$

${ }^{1}$ School of Nursing, Chitwan Medical College, Bharatpur, Nepal

${ }^{2}$ Chitwan Medical College Teaching Hospital, Bharatpur, Nepal

${ }^{3}$ School of Public Health, Chitwan Medical College, Bharatpur, Nepal

${ }^{4}$ Emergency Department, Chitwan Medical College Teaching Hospital, Bharatpur, Nepal

${ }^{5}$ Central Institute of Science and Technology, Kathmandu, Nepal

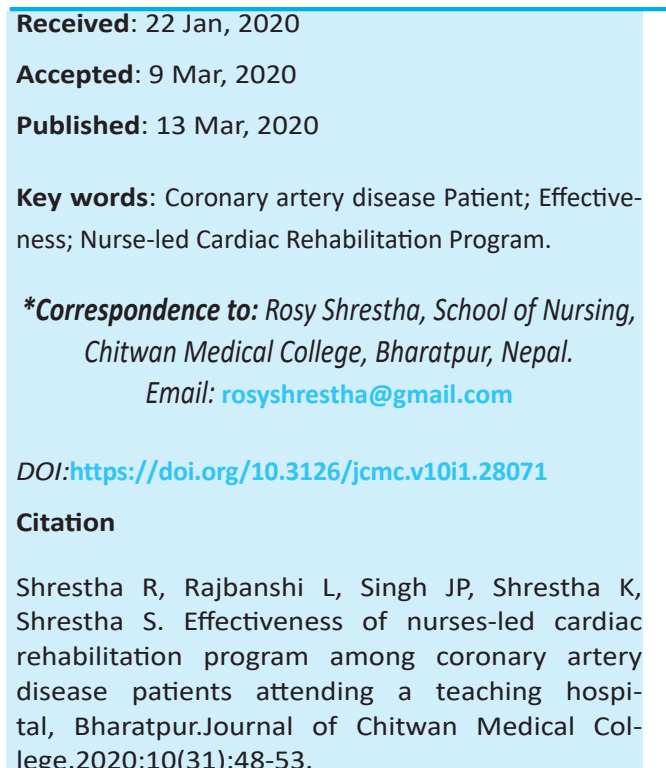
lege $2020 \cdot 10(31): 48-53$

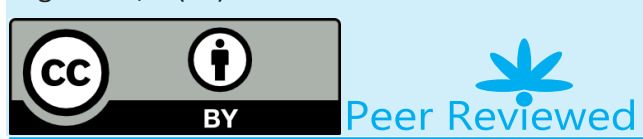

\section{INTRODUCTION}

Cardiovascular disease (CVD) is the leading cause of mortality worldwide, with majority of deaths occurring in low to middle income countries including Nepal. ${ }^{1}$ Among CVDs, Coronary artery disease (CAD) is the most common diagnosis. ${ }^{2-3}$ Nurses ought to play a key role in the prevention of $C A D^{4}$ and have the responsibility to educate patients on several aspects of the disease. Self-educational module can be used to raise awareness about cardiac rehabilitation (CR) program. Being aware of the CAD can be considered the first step to reduce the risk of cardiac complications. ${ }^{5}$ Nurse-led CR program designed to improve self-care management in patients with CAD showed significant difference in the physical dimension as well as in depression of CAD patients. ${ }^{6}$

An inadequate understanding of the disease may cause noncompliance with medical advice and unnecessary disease progression ${ }^{7}$; hence CAD knowledge is pivotal to the survival of patients. ${ }^{8}$ As of yet, patients' knowledge on CR is found to be suboptimal. ${ }^{9-10}$ Educational intervention program should be held as an effort to increase level of knowledge about the dis- ease. ${ }^{11}$ In a recent study out of 600000 cardiac patients, $12.2 \%$ participated in a CR program. After 1 year, there was a $2.2 \%$ mortality rate for cardiac rehabilitation participant's vs $5.3 \%$ for non-participants. ${ }^{12}$

Hence, knowledge regarding $C R$ should be considered vital in determining the effectiveness of an educational program. Few studies have addressed this issue therefore this study aims to find-out effectiveness of nurse-led CR program among CAD patients attending a tertiary level hospital at Bharatpur, Nepal.

\section{METHODS}

A pre-experimental one group pretest posttest research design was applied for this research to examine effectiveness of nurse-led cardiac rehabilitation with 85 CAD (angina pectoris, myocardial infarction and ischemic heart failure) patients attending outdoor department of Chitwan Medical College and Teaching Hospital (CMC-TH), Bharatpur, Nepal. Non-probability, consecutive sampling technique was chosen for this study. 
Inclusion criterias of this study were (1) patients who are clinically diagnosed with coronary Artery disease by cardiologist (2) residing in Chitwan district attending at OPD for follow up treatment at CMC-TH.

Data was collected by using structured tool consisting of four sections such as socio-demographic (total items-9) and disease related characteristics (total items-4), behaviour patterns (total items-6), and CADE-Q (total items-19). CADE-Q questionnaire for education on $C A D,{ }^{13}$ which include four areas such as (1) pathophysiology and signs and symptoms of the disease; (2) risk factors and lifestyle; (3) diagnosis, treatment, and medication; and (4) physical exercise. Each item has 4 alternatives or statements that correspond to a knowledge level: a correct statement representing 'full knowledge', a correct statement representing 'incomplete knowledge', an incorrect statement representing 'wrong knowledge', and an 'I do not know' statement representing no knowledge. Each alternative is scored as follows: 3 = complete knowledge; 1 = incomplete knowledge; and $0=$ wrong knowledge or "do not know." The sum of the final scores leads to a mean total knowledge (maximum of 57 points), which classifies into five level such as great (90-100\%), good (70-89\%), acceptable (50-69\%), poor (30-49\%), and insufficient $(<30 \%)$ about knowledge about coronary disease and $\mathrm{CR}^{5}$ The instrument was pretested and internal consistency of this tool was assessed using Cronbach ó ( $r=0.82$ ).

Data was collected in month of October to December, 2019 by using face to face interview method, it takes around 20 minutes to complete. Prior to data collection, the study was approved by the Institutional Review Committee (IRC) CMC-TH for the protection of human subjects. The participants were informed about the purpose of the study. In addition to this, they were also informed that responses would be kept confidential, and they would have the right to withdraw from the study at any time. Educational Package on cardiac rehabilitation (pamphlet) was developed based on AHA guideline and extensive literature search and distributed to the each respondent after pre-test data collection and after one month post-test was also collected from same sample to evaluate effectiveness of nurseled cardiac rehabilitation program.

Data was analyzed using statistical package for the social sciences (SPSS) version for window version 16.0. Descriptive (Percentage, frequency, mean and standard deviation) analysis also has been used to test and inferential statistic (Wilcoxon signed rank test) was used to find out effectiveness of educational package as well as pre and post test score difference of the respondents. Study sample of the participant are restricted by the classification level of knowledge in Ghisi et al. (2010) due to study design researchers had chosen. Therefore, to find a $p$-value the collapsing of range needed to be performed in order to classify the level of knowledge which was an acceptable (50-69\%), good (70\%-89\%) and an excellent knowledge (90\%-100\%) has to be combined and considered as an acceptable knowledge ( $\geq 50 \%)$. For insufficient $(<30 \%)$, and poor knowledge (30\%-49\%), these had been merged together and considered as non-acceptable knowledge with range $<50 \%$. The significance value was set at $p<0.05$.

\section{RESULTS}

Table 1 shows that the majority of the respondents were older aged $(43.5 \%)$, male $(52.9 \%)$, resided in urban (64.7\%), living single (50.6\%), Brahmin/Chhetri (52.9\%), Hindu (78.8\%), nuclear family (57.6), literate (54.1), and housework (42.4).

Table 1: Socio-demographic Characteristics of the Respondents $\mathrm{n}=85$

\begin{tabular}{|c|c|}
\hline Variables & Number (Percent) \\
\hline \multicolumn{2}{|l|}{ Age group (in years) } \\
\hline Adulthood(21-40) & $13(15.3)$ \\
\hline Middle age(41-60) & $35(41.2)$ \\
\hline Old aged( $(\geq 61)$ & $37(43.5)$ \\
\hline \multicolumn{2}{|c|}{ Mean age $\pm S D=56.95 \pm 15 ;$ Min $=15 \&$ Max 91 years } \\
\hline \multicolumn{2}{|l|}{ Sex } \\
\hline Male & $45(52.9)$ \\
\hline Female & $40(47.1)$ \\
\hline \multicolumn{2}{|l|}{ Place of Residence } \\
\hline Rural & $30(35.3)$ \\
\hline Urban & $55(64.7)$ \\
\hline \multicolumn{2}{|l|}{ Living Status } \\
\hline Living with family & $42(49.4)$ \\
\hline Living single* & $43(50.6)$ \\
\hline \multicolumn{2}{|l|}{ Ethnicity } \\
\hline Brahmin/Chhetri & $45(52.9)$ \\
\hline Janajati & $26(30.6)$ \\
\hline Dalit & $8(9.4)$ \\
\hline Others & $6(7.1)$ \\
\hline \multicolumn{2}{|l|}{ Religion } \\
\hline Hindu & $67(78.8)$ \\
\hline Non-Hindu & $18(21.2)$ \\
\hline \multicolumn{2}{|l|}{ Type of Family } \\
\hline Nuclear & $49(57.6)$ \\
\hline Joint & $36(42.4)$ \\
\hline \multicolumn{2}{|l|}{ Education } \\
\hline Literate & $46(54.1)$ \\
\hline Illiterate & $39(45.9)$ \\
\hline \multicolumn{2}{|l|}{ Occupation** } \\
\hline Agriculture & $26(30.6)$ \\
\hline Housework & $36(42.4)$ \\
\hline Service & $10(11.8)$ \\
\hline Business & $13(15.2)$ \\
\hline
\end{tabular}

* Included unmarried, divorced, widower/widow; **Included household activities like cooking, washing, cleaning, etc but do not earn money 
Table 2 shows that the disease related characteristics of the respondents. Majority of them had been diagnosed with Angina pectoris (56.5\%) and 1 year or above duration of treatment (56.5\%). Similarly, common mode of treatment was CMT (52.9\%), presence of HTN (68.2\%), DM (40.0\%) and high cholesterol (58.8\%) as common comorbidities among CAD patients.

Table 2: Disease related Characteristics of the Respondents $\mathrm{n}=85$

\begin{tabular}{|c|c|}
\hline Variables & Number (Percent) \\
\hline \multicolumn{2}{|l|}{ Clinical Diagnosis } \\
\hline Myocardial Infarction & $22(25.9)$ \\
\hline Angina Pectoris & $48(56.5)$ \\
\hline Ischemic heart disease & $15(17.6)$ \\
\hline \multicolumn{2}{|l|}{ Duration of Treatment } \\
\hline$<1$ year & $37(43.5)$ \\
\hline$\geq 1$ Years & $48(56.5)$ \\
\hline \multicolumn{2}{|l|}{ Mode of Treatment* } \\
\hline CMT & 45(52.9) \\
\hline $\mathrm{CMT}+\mathrm{PI}$ & $24(28.3)$ \\
\hline $\mathrm{CMT}+\mathrm{CABG}$ & $8(9.4)$ \\
\hline $\mathrm{CMT}+\mathrm{PI}+\mathrm{CABG}$ & $8(9.4)$ \\
\hline \multicolumn{2}{|c|}{ Presence of Co-morbidities } \\
\hline High blood pressure & $58(68.2)$ \\
\hline Diabetes Mellitus & $34(40.0)$ \\
\hline High Cholesterol & $50(58.8)$ \\
\hline
\end{tabular}

Table 3 shows that before and after behaviour patterns of respondents. Most of the respondents had smoking habit (before-56.5\% and after $44.7 \%$ ), tobacco use (before $48.2 \%$ and after $40.0 \%$ ), and alcohol consumption (before $52.9 \%$ and after 45.9\%), eat red meat (before $82.4 \%$ and after $69.4 \%$ ), eat fatty substance (before $82.4 \%$ and after $65.9 \%$ ) and sedentary life style (before $51.8 \%$ and $43.5 \%$ ).
Table 3: Behaviour Patterns of the Respondents $n=85$

\begin{tabular}{|l|c|c|}
\hline \multirow{2}{*}{ Variables } & Before diagnosis & After diagnosis \\
\cline { 2 - 3 } & Number (Percent) & Number (Percent) \\
\hline Smoking habit & $48(56.5)$ & $38(44.7)$ \\
\hline Tobacco use & $41(48.2)$ & $34(40.0)$ \\
\hline $\begin{array}{l}\text { Alcohol consump- } \\
\text { tion }\end{array}$ & $45(52.9)$ & $39(45.9)$ \\
\hline Eat red meat & $70(82.4)$ & 59(69.4) \\
\hline $\begin{array}{l}\text { Eat fatty sub- } \\
\text { stance }\end{array}$ & $70(82.4)$ & 56(65.9) \\
\hline $\begin{array}{l}\text { Sedentary life } \\
\text { style }\end{array}$ & $44(51.8)$ & $37(43.5)$ \\
\hline
\end{tabular}

Table 4 depicts median difference of pre and post-test on overall knowledge score regarding $C R$. The median difference has rose sharply from $17(I Q R=14-22)$ to $39(I Q R=32-44)$ after educational intervention. Using Wilcoxon signed rank test signifies the effectiveness of intervention was statistically significant $(<0.001)$.

Table 4: Median difference between Pre and Post-test Overall Scores Regarding Cardiac Rehabilitation $n=85$

\begin{tabular}{|c|c|c|}
\hline \multicolumn{2}{|c|}{$\begin{array}{c}\text { Mean Difference between Pre and } \\
\text { Post-test Overall Scores }\end{array}$} & \multirow{2}{*}{ *P-value } \\
\hline Pre-test & Post-test & \\
\hline Median (IQR) & Median(IQR) & \\
\hline $17(14-22)$ & $39(32-44)$ & $<0.001$ \\
\hline
\end{tabular}

Possible range 0-57; IQR (Inter Quartile Range) ; *Using Wilcoxon signed rank test

Table 5 shows the area of knowledge regarding CR among $C A D$ patients. The highest mean percent score of knowledge area was found in A1 (physiopathology, signs and symptoms area) for both pre (50.4\%) and post-test (69.4\%) and all areas of knowledge (A1-A4) were increased in post-test than pretest mean score and mean percent. This clearly indicates that educational intervention has positive effects on four areas of knowledge on CR among CAD patients.

Table 5: Areas of Knowledge regarding Cardiac Rehabilitation of the Respondents

$n=85$

\begin{tabular}{|c|c|c|c|c|c|c|c|c|}
\hline \multirow[b]{2}{*}{ *Areas } & \multirow[b]{2}{*}{ Items } & \multirow{2}{*}{$\begin{array}{c}\text { Possible } \\
\text { highest } \\
\text { score }\end{array}$} & \multicolumn{2}{|c|}{ Obtained range } & \multicolumn{2}{|c|}{ Mean \pm SD } & \multicolumn{2}{|c|}{ Mean\% } \\
\hline & & & pre & post & Pre & Post & Pre & Post \\
\hline $\mathrm{A} 1$ & 5 & 15 & $0-10$ & $2-15$ & $5.04 \pm 2.29$ & $10.41 \pm 2.81$ & 50.4 & 69.4 \\
\hline $\mathrm{A} 2$ & 8 & 24 & $0-15$ & $4-24$ & $6.58 \pm 3.17$ & $15.81 \pm 4.17$ & 43.86 & 65.87 \\
\hline A3 & 8 & 24 & $0-14$ & $3-24$ & $6.35 \pm 2.92$ & $15.86 \pm 4.35$ & 45.35 & 66.08 \\
\hline A4 & 8 & 24 & $0-17$ & $7-24$ & $7.69 \pm 3.45$ & $16.02 \pm 3.88$ & 45.23 & 66.75 \\
\hline
\end{tabular}

*A1-physiopathology, signals and symptoms; A2- risk factors and lifestyle; A3 - diagnostic, treatment and medicines; and, A4physical exercise; knowledge range $=0-100$ 
Table 6: Mean difference between Pre and Post-test CADE-Q Knowledge Scores Regarding Cardiac Rehabilitation

\begin{tabular}{|c|c|c|c|c|}
\hline \multirow{2}{*}{ Items no. } & \multirow{2}{*}{ Knowledge on CADE-Q } & Pre-test & Post-test & \multirow{2}{*}{ P-value* } \\
\hline & & Mean \pm SD & Mean \pm SD & \\
\hline Q1 & Coronary Artery Disease (CAD) is & $0.75 \pm 1.02$ & $2.15 \pm 1.19$ & $<0.001$ \\
\hline Q2 & Most influencing risk factors of $\mathrm{MI}$ & $0.88 \pm 1.14$ & $2.39 \pm 0.88$ & $<0.001$ \\
\hline Q3 & Typical symptom of CAD & $1.42 \pm 1.29$ & $2.25 \pm 1.11$ & $<0.001$ \\
\hline Q4 & Most accurate understanding of CAD & $0.96 \pm 1.14$ & $1.99 \pm 1.20$ & $<0.001$ \\
\hline Q5 & The best time of the day for exercise & $0.74 \pm 1.02$ & $1.76 \pm 1.27$ & $<0.001$ \\
\hline Q6 & Diagnosis and prognosis of CAD & $1.06 \pm 1.19$ & $2.26 \pm 1.12$ & $<0.001$ \\
\hline Q7 & Management of blood cholesterol & $1.05 \pm 1.31$ & $2.22 \pm 1.23$ & $<0.001$ \\
\hline Q8 & Use of "nitroglycerin" & $0.35 \pm 0.81$ & $1.85 \pm 1.38$ & $<0.001$ \\
\hline Q9 & Recommended Dietary components & $1.09 \pm 1.37$ & $2.09 \pm 1.32$ & $<0.001$ \\
\hline Q10 & Values for LDL and HDL cholesterol & $0.15 \pm 0.52$ & $1.71 \pm 1.41$ & $<0.001$ \\
\hline Q11 & Avoid carrying out usual exercise & $0.76 \pm 1.05$ & $1.98 \pm 1.24$ & $<0.001$ \\
\hline Q12 & Experiencing angina while walking & $1.06 \pm 1.19$ & $2.04 \pm 1.13$ & $<0.001$ \\
\hline Q13 & Knowledge about physical exercise & $1.15 \pm 1.32$ & $2.09 \pm 1.24$ & $<0.001$ \\
\hline Q14 & Physical Activity for CAD patient & $1.46 \pm 1.37$ & $2.13 \pm 1.25$ & 0.004 \\
\hline Q15 & Important to long term cardiac health & $0.91 \pm 1.14$ & $1.99 \pm 1.25$ & $<0.001$ \\
\hline Q16 & Pattern for exercise activity & $1.14 \pm 1.32$ & $2.39 \pm 1.07$ & $<0.001$ \\
\hline Q17 & Appropriate guidance for HTN patient & $0.85 \pm 1.12$ & $2.24 \pm 1.16$ & $<0.001$ \\
\hline Q18 & Knowledge on psychological stress & $0.87 \pm 1.12$ & $1.61 \pm 1.36$ & 0.001 \\
\hline Q19 & $\begin{array}{l}\text { Interventions, which can improve a patient's quality } \\
\text { of life }\end{array}$ & $0.72 \pm 1.13$ & $1.46 \pm 1.37$ & $<0.001$ \\
\hline
\end{tabular}

Possible range 0-3; *Using Wilcoxon signed rank test

Table 6 reveals mean difference of 19 items of CADE-Q for pre and post-test. As given, pretest mean difference was found to be lower than post-test in each item, which is statistically significant at the level of $p$-value $<0.005$ ) by using Wilcoxon signed rank test.
Table 7 shows the level of knowledge regarding CR among CAD patients. The level of knowledge classified into five as shown in table. The pre-test percentage on given knowledge illustrates higher proportion on Poor (52.9\%) level of knowledge while in post-test higher proportion was on Good (45.9\%).

Table 7: Level of Knowledge regarding Cardiac Rehabilitation of the Respondents

\begin{tabular}{|c|c|c|c|}
\hline \multirow{2}{*}{ Knowledge Level } & \multirow{2}{*}{ Sum of points } & \multicolumn{2}{|c|}{ Number (Percent) } \\
\hline & & Pre-test & Post-test \\
\hline Excellent $(90-100 \%)$ & $51-57$ & $0(0.00)$ & $3(3.5)$ \\
\hline Good (70-89\%) & $40-50$ & $0(0.00)$ & 39 (45.9) \\
\hline Acceptable (50-69\%) & $29-39$ & $3(3.5)$ & $33(38.8)$ \\
\hline Poor (30-49\%) & $17-28$ & $45(52.9)$ & $10(11.8)$ \\
\hline Insufficient (<30\%) & $<17$ & $37(43.6)$ & $0(0.00)$ \\
\hline Total (0-100\%) & $0-57$ & $85(100)$ & $85(100.0)$ \\
\hline
\end{tabular}

Figure 1 reveals that patients scored $96.47 \%$ as non-acceptable $(<50 \%)$ knowledge score on pre-test and remarkable decline on post-test being $11.76 \%$. Respondents' score on pre-test was quiet low being $3.53 \%$ as acceptable score $(\geq 50 \%)$, however in post-test score upsurge by $88.24 \%$. This designates that the educational intervention on CR is effective for CAD patient. 


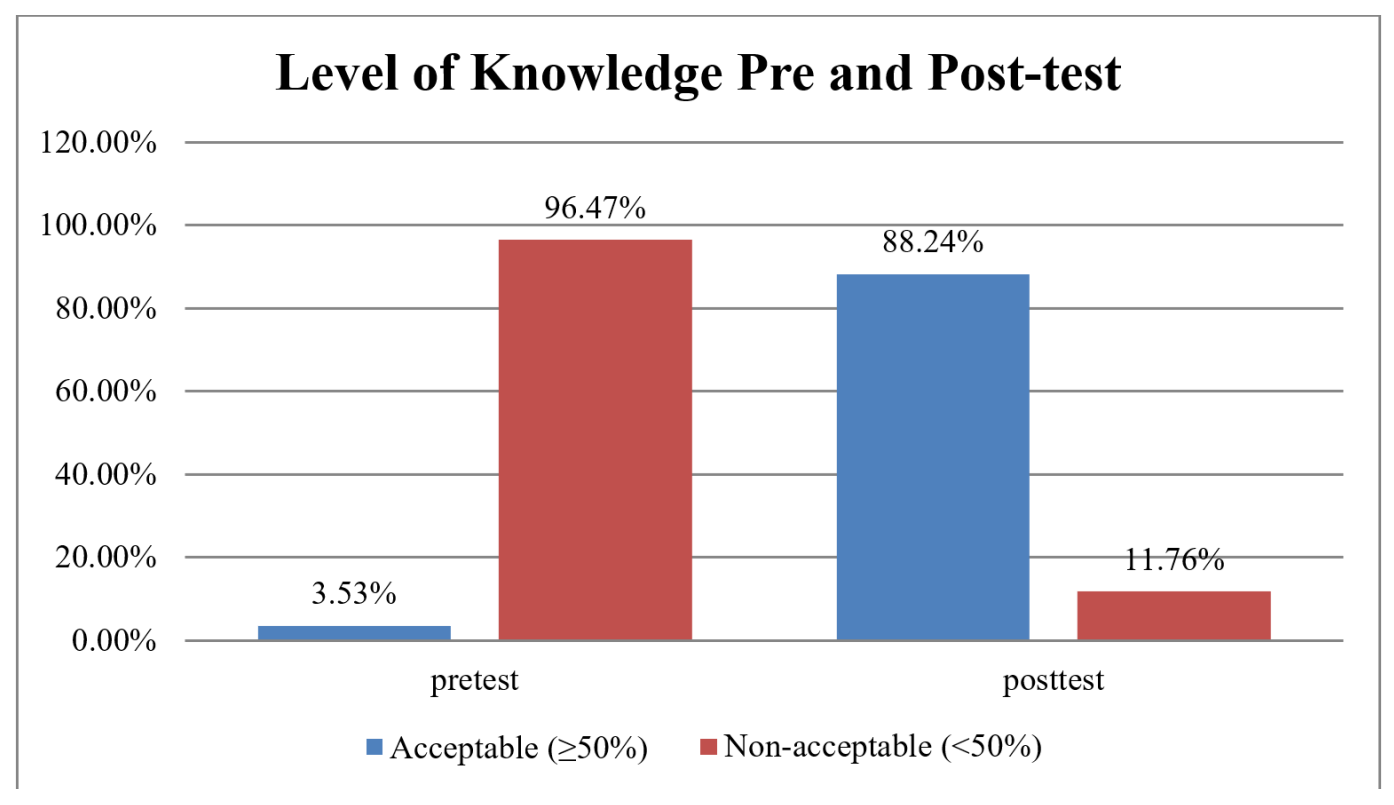

Figure1: Level of Knowledge regarding CR according to Pre and Post-test Score

Table 8 demonstrates the outcomes of comparison of nonacceptable and acceptable level of knowledge with pre and post-test score among study sample $(n=85)$. There was statistically significance difference between pre and post-test score with level of knowledge in this study $(p=<0.001)$. The non-acceptable knowledge during pre-test has declined in post-test whereas for an acceptable knowledge there was rise in posttest compared to pre-test score.

Table 8: Comparison of Level of Knowledge of Cardiac Rehabilitation Pre and Post- Educational Intervention Program $\mathrm{n}=85$

\begin{tabular}{|l|c|c|c|}
\hline \multicolumn{1}{|c|}{ Knowledge Level } & \multicolumn{1}{|c|}{ Pre-test } & Post-test & \\
& $\begin{array}{c}\text { Number } \\
\text { (Percent) }\end{array}$ & $\begin{array}{c}\text { Number } \\
\text { (Percent) }\end{array}$ & p-value \\
\hline Non-acceptable $(<50 \%)$ & $82(96.47 \%)$ & $10(11.8 \%)$ & \multirow{2}{*}{$<0.001$} \\
\cline { 1 - 3 } Acceptable $(\geq 50 \%)$ & $3(3.53 \%)$ & $75(88.2 \%)$ & \\
\hline
\end{tabular}

\section{DISCUSSION}

Findings of this study suggested that the educational intervention program was successful in bringing significant changes in the knowledge about cardiac rehabilitation in CAD patients. The result from this study was found to be consistent with other interventional studies. ${ }^{13,19-23}$ Regarding selected variables, majority were male, literate, continues medical treatment, hypertensive. These findings were similar to the findings of a study done in Brazil. ${ }^{5}$ After diagnosis of disease they changed their behaviour patterns which was also consistent with a study done in India. ${ }^{12}$

This study also reported that median score was improved in post-test than pre-test. The non-acceptable knowledge level during pre-test has declined in post-test whereas for an accept- able knowledge there was rise in post-test compared to pretest score. This finding was supported by another study done in Malaysia ${ }^{13}$ and Nepal. $^{21}$

Similarly, in pretest majority of respondent had poor knowledge on cardiac rehabilitation. However, after receiving educational intervention program their level of knowledge regarding the CR improved. This finding was consistent with various other studies. ${ }^{13,15}$ Moreover, a systematic review reported that cardiac rehabilitation program have shown to reduce risk factors, such as clinical and behaviour related intervention including physical, diet, and smoking habit. These core components of CR program intervention lead to improved knowledge score among CAD patient. ${ }^{22}$

Due to use of only one group pre-test and post-test design the result of this study might have been affected by maturation and history effect. Likewise sampling might also have affected the result or conclusion of the study and cannot represent an entire population.

\section{CONCLUSION}

It is concluded that level of knowledge on cardiac rehabilitation among CAD patients in Nepal was found to be non-acceptable in pre-test however in the post test, level of knowledge of the CAD patient raised to an acceptable level after educational intervention. It is also reported that there is an improvement in the level of knowledge after an immediate post-test data from non-acceptable to an acceptable level of knowledge compared to pre-test data. Thus, we can conclude that the health education regarding $C R$ is very crucial to increase the level of knowledge among CAD patients. Hence, every tertiary level hospital should have a nurse-led cardiac rehabilitation unit in their institution for a better prognosis and quality of life of patients suffering from CAD. 


\section{AKNOWLEDGEMENTS}

This study was made possible by support and co-operation of the cardiology team and supporting staffs of the OPD of CMC$\mathrm{TH}$. We are also thankful to the respondents for their valuable information and time for this study.
CONFLICT OF INTEREST: None declared

\section{FINANCIAL DISCLOSURE: None}

13. Mohamad N, Ikhsan ND, Ismail RA, Kamaruddin AF, Mulud ZA. The Effect of Health Education Program on Knowledge of Coronary Heart Disease (CHD) Among Public in Puncak Alam, Selangor. Advanced Science Letters. 2018 Jan 1;24(1):556-8. [DOI]

14. de Melo Ghisi GL, Oh P, Thomas S, Benetti M. Assessment of patient knowledge of cardiac rehabilitation: Brazil vs Canada. Arq Bras Cardiol. 2013 Sep 1;101(3):255-62. [DOI]

15. Shrestha R. \& Shrestha, S. Awareness regarding cardiac rehabilitation among patients with coronary heart disease attending a cardiac care center, Kathmandu valley. Nepalese Heart Journal, 2019; 16(1):47-50.

16. Andsoy, I.I., Tastan, S., Iyigun, E., \& Kopp, L.R. Knowledge and attitude towards cardiovascular disease in a population of North Western Turkey: A cross-sectional Survey. International Journal of Caring Sciences,2015; 8(1), 115. [DOI]

17. Zhou Y, Li J, Du S, Du X, Fu C, Cao C, Wang Y. Cardiac rehabilitation knowledge in patients with coronary heart disease in Baoding city of China: A cross-sectional study. International Journal of Nursing Sciences. 2017 Jan 10;4(1):24-8. [DOI]

18. Ray M, Guha S, Ray M, Kundu A, Ray B, Kundu K, Goswami S, Bhatt DL, Selker HP, Goldberg RJ. Cardiovascular health awareness and the effect of an educational intervention on school-aged children in a rural district of India. Indian heart journal. 2016 Jan 1;68(1):43-7. [DOI]

19. Eshah NF, Bond AE, Froelicher ES. The effects of a cardiovascular disease prevention program on knowledge and adoption of a heart healthy lifestyle in Jordanian working adults. European Journal of Cardiovascular Nursing. 2010 Dec;9(4):244-53. [DOI]

20. Southard B, Southard D, Nuckolls J. Clinical trial of an internet-based case a management system for secondary prevention of heart disease. Journal of Cardiopulmonary Rehabilitation. 2003;23(5):341-8. [DOI]

21. Shrestha R. \& Shrestha S. Effectiveness of educational intervention on life style management among coronary heart disease patients attending a cardiac a care Centre in Kathmandu. Journal of Institute of Medicine. 2016; 38(1): 20-25.

22. Strid C, Lingfors H, Fridlund B, Mårtensson J. Lifestyle changes in coronary heart disease-Effects of cardiac rehabilitation programs with focus on intensity, duration and content: A systematic review. Open Journal of Nursing. 2012;2(4):420-30. [DOI]

23. Tawalbeh LI, Ahmad MM. The effect of cardiac education on knowledge and adherence to healthy lifestyle. Clinical Nursing Research. 2014;23(3): 245-58. [DOI] 